DOI: $10.21767 / 2471-299 X .100014$

\title{
Dysphagia: A Geriatric Giant?
}

\section{David G Smithard ${ }^{1,2 *}$}

${ }^{1}$ King's College Hospital NHS Foundation Trust, London, UK

${ }^{2}$ Department of electronics and Digital Arts, University of Kent, UK

*Corresponding author: Smithard DG, Geriatrician, King's College Hospital NHS Foundation Trust, London, UK, Tel: +44 1689 863000 ; E-mail: David.Smithard@nhs.net

Rec date: Dec 31, 2015; Acc date: Jan 22, 2016; Pub date: Jan 25, 2016

Copyright: @ 2016 Smithard DG. This is an open-access article distributed under the terms of the Creative Commons Attribution License, which permits unrestricted use, distribution, and reproduction in any medium, provided the original author and source are credited.

\section{Abstract}

With increasing age there are changes to the physiology of all aspects of swallowing. Despite these changes, the majority of older people will swallow safely. With increasing frailty the number of people presenting with dysphagia increases either in the presence of acute illness or with co morbidity; with significant number living in institutions.

The aetiology of dysphagia is multiple and is associated with increased dependency and mortality and as such dysphagia meets the criteria to be classified as a geriatric syndrome or giant.

This paper presents the case for dysphagia to be recognised as a geriatric giant.

Keywords: Physiology; Dysphagia; Respiration

\section{Introduction}

The worldwide population is increasing, such that it is predicted that there will be 2 billion over the age of 65 years by 2050; the greatest proportional increase will be in those over the age of 85 years. Accompanying this will be an increase In people living longer with long term conditions and a consequent increase in frail older people.

Old age is frequently accompanied by many long-term conditions that affect health. Many old people will have multiple long-term conditions (e.g. ischaemic heart disease, diabetes, dementia)

Dysphagia, difficulty in swallowing, will accompany many long term conditions and may be latent in many frail older people, and is associated with increasing dependency and death. The time has come to fully recognise dysphagia as a Geriatric Giant /Syndrome.

To be recognised as a Geriatric Syndrome/Giant [1] dysphagia has to meet accepted recognised criteria (Table 1). This short paper will outline the reasons why it should be considered thus.
Table 1 Factors required to be considered as a Geriatric Giant.

\begin{tabular}{|l|l|}
\hline Factor for Geriatric Giant & Dysphagia \\
\hline Age & $\checkmark$ \\
\hline Symptom & $\checkmark$ \\
\hline Cognitive Function & $(\checkmark)$ \\
\hline Functional Impairment & $(\checkmark)$ \\
\hline Common & $\checkmark$ \\
\hline Multifactorial & $\checkmark$ \\
\hline Morbidity & $\checkmark$ \\
\hline Outcome & $\checkmark$ \\
\hline
\end{tabular}

\section{The Normal Swallow}

The essential function of the swallowing process is to transfer food from the mouth to the stomach via the oesophagus, a simple, but complex process. The process of swallowing is separated into three phases, oral, pharyngeal and oesophageal [2,3]. The oral phase, to be efficient, requires adequate lip closure, a functioning tongue and the presence of saliva; the pharyngeal phase is a transfer phase between the mouth and the oesophagus, but it is a shared space with respiration. Therefore the airway needs to be protected during this phase. Then to enter the oesophagus the upper oesophageal sphincter or cricopharyngeus needs to relax.

The pharyngeal phase of the swallow is a complex reflex, coordinated by the swallowing centres within the medullary pontine area of the brainstem [4] This reflex is modified via the feedback loop between the pharynx, hyoid muscles and tongue to the cortex regarding bolus characteristics (volume and consistency), which then regulates the timing of events during the pharyngeal swallow, but not the sequence of events $[5,6]$.

Protection of the airway is a complex process that involves the closure of the larynx by the false and true vocal folds, elevation and rotation forward of the larynx and backward pressure from the base of the tongue. The Naso-pharynx is protected by elevation of the soft palate and the forward movement of the posterior pharyngeal wall. As the larynx 
closes off, respiration ceases to be followed by expiration when the swallow has been completed.

The neurological innervation of swallowing (Figure 1) comprises 6 cranial nerves as well as the pharyngeal plexus. Cortical representation is diffuse, but work by Hamdy and colleagues have shown that although cortical representation is bilateral, one hemisphere is dominant. This dominance has importance when the brain is injured (stroke, TBI), and if the injury has affected the dominant side, the response of the non-dominant hemisphere is important to recovery $[4,7-9]$.

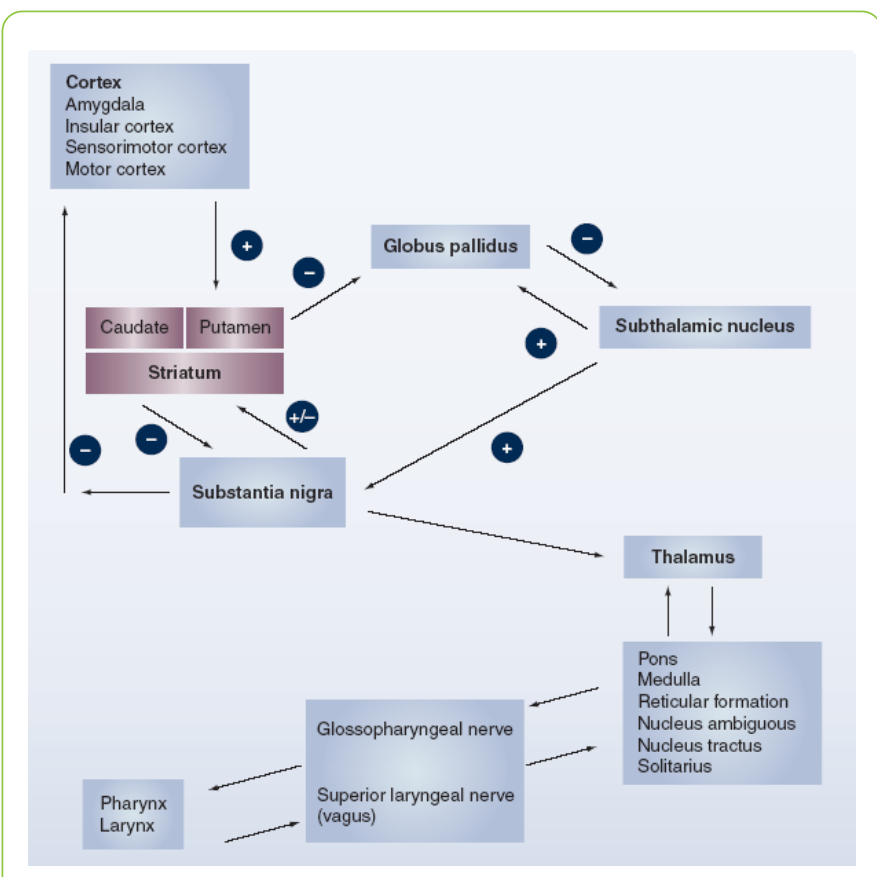

Figure 1 Neurological control of swallowing.

Food recognition requires more than taste alone. The recognition of a particular food relies on vision, smell, proprioception and memory. Unfortunately age brings changes to these systems. Age may result in failing eyesight due to macular degeneration, cataracts or reduced visual field/ neglect with stroke [10]. Memory may be reduced due to dementia resulting in the inability to recall previous experiences with food. Dyspraxia of eating/swallowing may occur [11-13]. Not least to cope with the joys of having dentures and eating.

Saliva is crucial for a swallow and although volumes are reduced, adequate volumes are still present, until there is a perturbation on the system due to illness or medication (Table 2) $[14,15]$.

With age there are changes in the ability to swallow, though, not infrequently the older person may not recognise that any changes to their swallow has occurred. Within the peripheral neurological system, there is a reduction in nerve conduction and increased conduction times due to myelin degeneration $[11,16]$, which reduces the effectiveness of the feedback loop.
There is a reduction in proprioception both in the tongue and lips reducing the ability to identify texture and viscosity [17]

Table 2 Medication and affect of swallowing.

\begin{tabular}{|c|c|}
\hline Medication & Affect of Swallowing \\
\hline \multicolumn{2}{|l|}{ Anticholinergic Effects } \\
\hline \multicolumn{2}{|l|}{ Antidepresants } \\
\hline Incontinence & Dry Mouth \\
\hline Opiates & Confusion \\
\hline Antipsychotics & Sedation \\
\hline \multicolumn{2}{|l|}{ Central Effects } \\
\hline \multicolumn{2}{|l|}{ Anxiolytics } \\
\hline Sleeping Tablets & Sedation \\
\hline Medication for Epilepsy & Incoordination \\
\hline \multirow[t]{2}{*}{ Opiate Medication } & Dry Mouth \\
\hline & Altered Taste \\
\hline Antibiotics & Oral Infection \\
\hline Anti-inflammatory Agents & Altered Taste \\
\hline Medication for diabetes (Metformin) & Altered Taste \\
\hline \multicolumn{2}{|l|}{ Anti-Hypertensive Agents } \\
\hline ACE-I & Altered Taste \\
\hline Calcium Channel Blockers & Dry Mouth \\
\hline Diuretics & Dry Mouth \\
\hline Cox-2 Inhibitors & Reduced Cough \\
\hline
\end{tabular}

The sequence of events during swallowing does not change, but the timing of events and the degree of change is different. The oro-pharyngeal phase is prolonged [18] with a prolonged transit time [19] and there are more cortical areas activating during swallow suggesting a more concentrated effort [20].

The changes in the oral phase will include prolonged oral bolus transit [21]; there is an increase in the dippers as opposed to tippers of tongue position [22] prior to the propulsion of the bolus towards the pharynx.

Changes in the swallowing process may be affected due to frailty and sarcopenia rather than an overt disease process [23]. As a consequence of both of these processes, skeletal muscle is weak (poor quality muscle fibres and reduction in number) which may result in reduced tongue function and pharyngeal contraction. . Isometric tongue pressures although reduced, have no clinical effect as the tongue is working at submaximal pressures [24], Calve et al. have suggested that weakness in the tongue due to sarcopenia reduces tongue propulsion and increases risk of aspiration [24]. However Logemann did note that women exhibit reduction in tongue base movement [25]. Smaller volumes are swallowed but a larger bolus is required to trigger a reflex swallow [26,27].

Laryngeal elevation, rotation and forward movement are reduced. Laryngeal vestibule closure is delayed and maximal hyolaryngeal excursion is delayed [24]. The final defence of the airway during swallowing is the cough reflex. A weak cough reflex increases the risk of aspiration and pneumonia [28], with normal ageing there is no change in the cough reflex, 
however the threshold concentration for citric acid does increase in the presence of dementia $(2.6 \pm 4.0 \mathrm{mg} / \mathrm{mL}$ in control subjects; $37.1 \pm 16.7 \mathrm{mg} / \mathrm{mL}$ in patients with dementia; $>360 \mathrm{mg} / \mathrm{mL}$ in survivors of aspiration pneumonia).

The ability to clear the pharynx is also reduced in those over 65 years of age (18\% vs $38 \%)$ requiring the person to undertake repeated swallows. This is evident with the need to undertake recurrent hyoid gestures [25] table. Pharyngeal transit times increase. The larynx has a tendency to have a lower resting height and does not elevate as much in younger people.

\section{Prevalence of Dysphagia}

The prevalence of dysphagia in the general population is $16-23 \%$ [29-32] increasing to $27 \%$ in those over 76 years of age. Many older people will have swallowing problems. The prevalence of dysphagia increases with the degree of frailty present and the degree of dependence irrespective of ethnicity $[13,16,33-37]$. In the presence of neurological disease (dementia/Parkinson's Disease/Stroke) the prevalence is higher than the general population (Table 3, Adapted from Clavé et al. [38]). Frail older people readmitted with pneumonia may have a prevalence as high as 55\% [39] even greater in those admitted from nursing homes [40].

Problems may present with fatigability whilst eating, coughing on certain consistencies and at times with behavioural issues such as food refusal, spitting and the hiding of food.

$24 \%$ of older people consider developing swallowing problems a natural consequence of getting old [35], many old people slowly adapt by eating slower, changing food consistencies and taking smaller portion sizes.

Table 3 Population and evaluation method.

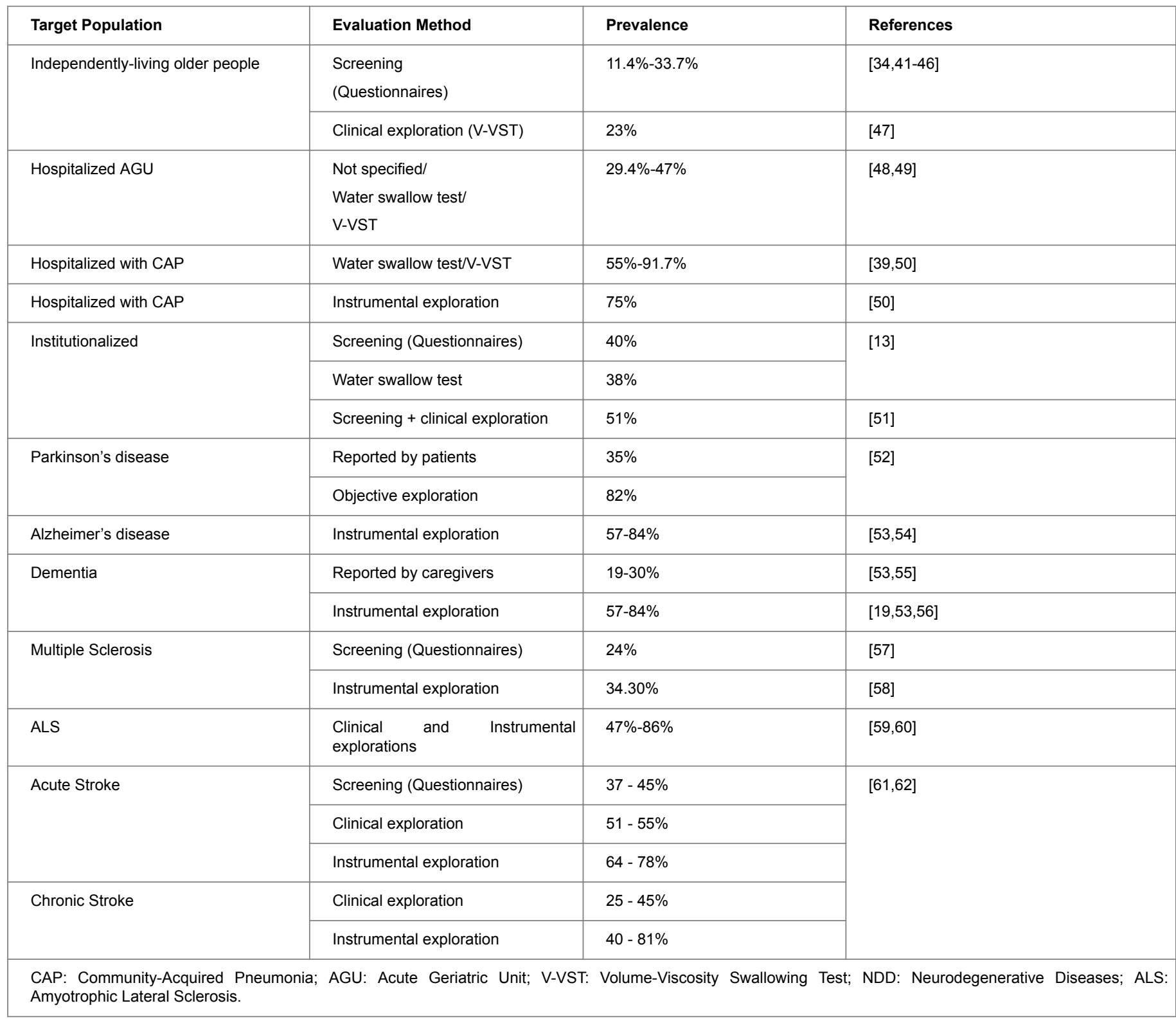


The consequences of swallowing problems (Table 4) may be very little for some, but in others it will result in poor nutrition, reduced muscle strength, immobility, poor wound healing, aspiration and pneumonia $[63,64]$. The consequence for society is a greater use of health resources at time when there are already pressures on health systems. Mortality at 30 days from pneumonia has been found to be $22.9 \%$ compared to $8.3 \%$ in those with dysphagia and at one year the mortality rate is doubled $[65,66]$.

Table 4 Complications of dysphagia.

\begin{tabular}{|l|}
\hline Cough \\
\hline Aspiration \\
\hline Recurrent Chest Infection \\
\hline Pneumonia \\
\hline Malnutrition \\
\hline Dehydration \\
\hline Hypoxia \\
\hline Increased dependency \\
\hline Frailty \\
\hline Death \\
\hline
\end{tabular}

The relative risk of pneumonia is 6 fold for those greater than 75 years compared to those under 65 . Those living in care homes are 33 times as likely to be admitted to hospital with a pneumonia compared to those living in the community [37]. Oral health is an important factor in the occurrence of pneumonia. With poor dental care and the presence of dentures, not only is mastication less effective, the risk of oral infection with anaerobes and yeast is quite high. Keeping the mouth clean, particularly in the most dependent people will reduce the risk of infection $[67,68]$.

What should not be under estimated is the psychological consequences of dysphagia such as anxiety, and depression $[69,70]$ and quality of life in general [71].

\section{Co-existent Long Term Conditions}

It is an unfortunate fact that as people age, they suffer from multiple chronic diseases all of which can exacerbate or result in dysphagia. The commonest neurological medical complaints associated with dysphagia are stroke (50\%), dementia (up to 93\%), Parkinson's Disease (39\%) and Motor Neurone Disease. However cardiac failure, chronic obstructive lung disease and rheumatoid arthritis are other medical conditions that are associated with dysphagia $[72,73]$.

\section{What can be done?}

As has been mentioned earlier, the poor outcome associated with dysphagia has a multifactorial component, either that due to the dysphagia itself (aspiration, infection, weight loss) or secondary to underlying risk or aetiological factors (dementia, diabetes, smoking).

The management of dysphagia is similar to other long term conditions including the management of environmental factors (such as smoking, alcohol, medication)

The first point about management is to recognise that there is a problem. Asking whether the ability to eat has changed (slower, different textures, painful) and where the admission has been due to pneumonia in older, frail populations consider aspiration as a cause.

The management of dysphagia, and particularly its consequences, in older people may be simple. The crucial point is to remember to look for it; suspect that dysphagia may be a problem. Many frail older people may not complain of dysphagia until they become unwell, and then due to their lack of physiological reserve, dysphagia ensues [74]. It is important to work with the older person and be prepared to take risks. To many the mere factor of eating and drinking is more important than the risk of aspirating.

When older people have swallowing difficulties, appropriate investigation needs to be undertaken. This includes a swallow screen $[75,76]$, swallow assessment by speech and language pathologists and then investigation typically with videofluoroscopy or Fibreoptic endoscopic evaluation of swallowing . In some cases manometry is required to detect oesophageal problems or $\mathrm{pH}$ monitoring for reflux [77].

When dysphagia is suspected a referral should be made to a speech and language therapist for a full assessment of swallowing, clinically initially and later via videofluoroscopy or FEES depending on clinical need or availability. This should be followed by advice as to food texture, speed of swallowing and swallowing manoeuvres. Where there evidence of significant cognitive impairment a more pragmatic approach may have to be taken, such as watching them eat a meal or take a drink.

Other simple measures include: review medication, stop anything that may worsen the ability to swallow (drugs causing a dry mouth; drowsiness etc), check dental plates for infection; check positioning and if appropriate, how people are fed.

Within the hospital setting, both the Matero Hospital in Barcelona ( $\mathrm{P}$ Clavé personal communication) and the Royal Berkshire in Reading UK (M Gosney personal communication) have developed projects aimed at reducing aspiration including the use of elevation of the head end of the bed, or sitting upright at meal times, mouth wash and routine screening. In Japan [78], dental hygienists and dentists are employed to improve mouth care. Recent work in stroke patients has suggested that the use of Metoclopramide may reduce the risk of aspiration [79], whereas routine prescribing of antibiotics did not help $[80,81]$.

\section{A Geriatric Syndrome/Giant}

The term geriatric Syndrome was first used in 1909 [1]. Originally there were four recognised syndromes or giants, this has been added to in recent years with Sarcopenia and frailty 
[81]. Is dysphagia, therefore, a geriatric syndrome? Geriatric syndromes are defined as "conditions" experienced by the older persons that occur intermittently, may be triggered by acute insults and often are linked to subsequent functional decline [74].

As we have noted above, dysphagia and swallowing in old age are complex and associated with many different aetiologies (Figure 2). It is recognised that dysphagia, frailty and poor outcome (including death) are intertwined.

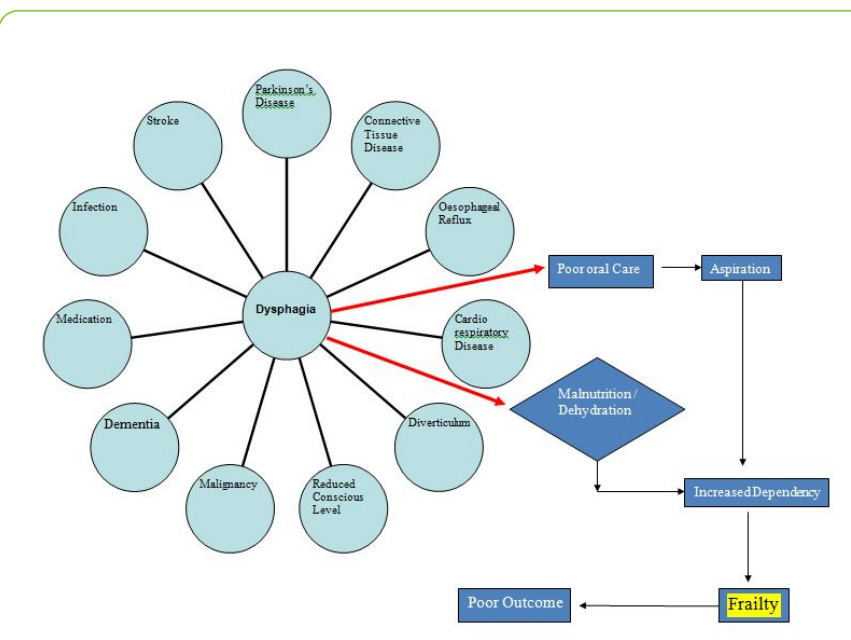

Figure 2 Dysphagia: A geriatric giant. Aetiology and long term effects.

Therefore, dysphagia is a geriatric giant in that it is common in old age and is a result of many processes, has an adverse effect on outcome in its own right but is also a non-specific indicator of functional decompensation [82], carries a significant morbidity and decline. Geriatric giants are symptoms and not diagnoses in their own right; require a multidisciplinary approach to management and treatment

\section{Summary}

Dysphagia is a common problem that accompanies ageing. It has many aetiologies, many of which overlap with other Giants. Dysphagia is associated with a poor outcome, including increasing frailty, institutionalisation and mortality. It is for these reasons that it should be recognized as a true Geriatric Giant.

\section{References}

1. Nascher IL. Geriatrics (1914) The diseases of old age and their treatment. University of California Libraries.

2. Daniels SK, Brailey K, Foundas AL (1999) Lingual discoordination and dysphagia following acute stroke: analyses of lesion localization. Dysphagia 14: 85-92.

3. Schindler JS, Kelly JH (2002) Swallowing disorders in the elderly. Laryngoscope 112: 589-602.

4. Jean A (2001) Brain stem control of swallowing: neuronal network and cellular mechanisms. Physiol Rev 81: 929-969.
5. Smithard DG (2002) Swallowing and stroke. Neurological effects and recovery. Cerebrovasc Dis 14: 1-8.

6. Hamdy S, Aziz Q, Rothwell JC, Hobson A, Barlow J, et al. (1997) Cranial nerve modulation of human cortical swallowing motor pathways. Am J Physiol 272: G802-808.

7. Hamdy S, Aziz Q, Rothwell JC, Singh KD, Barlow J, et al. (1996) The cortical topography of human swallowing musculature in health and disease. Nat Med 2: 1217-1224.

8. Nicosia MA, Hind JA, Roecker EB, Carnes M, Doyle J, et al. (2000) Age effects on the temporal evolution of isometric and swallowing pressure. J Gerontol A Biol Sci Med Sci 55: M634M640.

9. Suzuki M, Asada Y, Ito J, Hayashi K, Inoue H, et al. (2003) Activation of cerebellum and basal ganglia on volitional swallowing detected by functional magnetic resonance imaging. Dysphagia 18: 71-7.

10. Smithard DD, Smithard DG (2015) The aetiology of visual impairment in the older person and the influence of the multidisciplinary pathway on patient lifestyle. Geriatric Medicine 25-30.

11. Humbert IA, Robbins J (2008) Dysphagia in the elderly. Phys Med Rehabil Clin N Am 19: 853-866, ix-x.

12. Leslie P, Carding PN, Wilson JA (2003) Investigation and management of chronic dysphagia. BMJ 326: 433-436.

13. Nogueira D, Reis E (2013) Swallowing disorders in nursing home residents: how can the problem be explained? Clin Interv Aging 8: 221-227.

14. Humphrey SP, Williamson RT (2001) A review of saliva: normal composition, flow, and function. J Prosthet Dent 85: 162-169.

15. Walls AW, Steele JG (2004) The relationship between oral health and nutrition in older people. Mech Ageing Dev 125: 853-857.

16. Ney DM, Weiss JM, Kind AJ, Robbins J (2009) Senescent swallowing: impact, strategies, and interventions. Nutr Clin Pract 24: 395-413.

17. Hiss SG, Treole K, Stuart A (2001) Effects of age, gender, bolus volume, and trial on swallowing apnea duration and swallow/ respiratory phase relationships of normal adults. Dysphagia 16: 128-135.

18. Butler SG, Stuart A, Leng X, Rees C, Williamson J, et al. (2010) Factors influencing aspiration during swallowing in healthy older adults. Laryngoscope 120: 2147-2152.

19. Rofes L, Arreola V, Romea M, Palomera E, Almirall J, et al. (2010) Pathophysiology of oropharyngeal dysphagia in the frail elderly. Neurogastroenterol Motil 22: 851-858.

20. Teismann IK, Steinstraeter O, Schwindt W, Ringelstein EB, Pantev C, et al. (2010) Age-related changes in cortical swallowing processing. Neurobiol Aging 31: 1044-1050.

21. Logemann JA (1998) The evaluation and treatment of swallowing disorders. Curr Opin Otolaryngol Head Neck Surg 6: 395-400.

22. Dodds WJ (1989) Physiology of swallowing. Dysphagia 3: 171-178.

23. Clavé $P$, Verdaguer A, Arreola V (2005) [Oral-pharyngeal dysphagia in the elderly]. Med Clin (Barc) 124: 742-748.

24. Butler SG, Stuart A, Leng X, Wilhelm E, Rees C, et al. (2011) The relationship of aspiration status with tongue and handgrip 
strength in healthy older adults. J Gerontol A Biol Sci Med Sci 66: 452-458.

25. Logemann JA, Pauloski BR, Rademaker AW, Kahrilas PJ (2002) Oropharyngeal swallow in older and younger women: videofluoroscopic analysis. J Speech Hearing and Language Research 45: 434-445

26. Verdú E, Ceballos D, Vilches JJ, Navarro X (2000) Influence of aging on peripheral nerve function and regeneration. J Peripher Nerv Syst 5: 191-208.

27. Daggett A, Logemann J, Rademaker A, Pauloski B (2006) Laryngeal penetration during deglutition in normal subjects of various ages. Dysphagia 21: 270-274.

28. Ebihara S, Ebihara T, Kohzuki M (2012) Effect of aging on cough and swallowing reflexes: implications for preventing aspiration pneumonia. Lung 190: 29-33.

29. Chiocca JC, Olmos JA, Salis GB, Soifer LO, Higa R, et al. (2005) Prevalence, clinical spectrum and atypical symptoms of gastrooesophageal reflux in Argentina: a nationwide population based study. Alimentary Pharmacology \& Therapeutics 22: 331-342.

30. Cho YS, Choi MG, Jeong JJ, Chung WC, Lee IS, et al. (2005) Prevalence and clinical spectrum of gastroesophageal reflux: a population-based study in Asan-si, Korea. Am J Gastroenterol 100: 747-753.

31. Eslick GD, Talley NJ (2008) Dysphagia: epidemiology, risk factors and impact on quality of life--a population-based study. Aliment Pharmacol Ther 27: 971-979.

32. Ruth M, Månsson I, Sandberg N (1991) The prevalence of symptoms suggestive of esophageal disorders. Scand J Gastroenterol 26: 73-81.

33. Regan J, Sowman R, Walsh I (2006) Prevalence of Dysphagia in acute and community mental health settings. Dysphagia 21 95-101.

34. Bloem BR, Lagaay AM, van Beek W, Haan J, Roos RA, et al. (1990) Prevalence of subjective dysphagia in community residents aged over 87. BMJ 300: 721-722.

35. Chen PH, Golub JS, Hapner ER, Johns MM 3rd (2009) Prevalence of perceived dysphagia and quality-of-life impairment in a geriatric population. Dysphagia 24: 1-6.

36. Ekberg $\mathrm{O}$, Hamdy $\mathrm{S}$, Woisard V, Wuttge-Hannig A, Ortega $\mathrm{P}$ (2002) Social and psychological burden of dysphagia: its impact on diagnosis and treatment. Dysphagia 17: 139-146.

37. Marik PE, Kaplan D (2003) Aspiration pneumonia and dysphagia in the elderly. Chest 124: 328-336.

38. Clavé P, Shaker R (2015) Dysphagia: current reality and scope of the problem. Nat Rev Gastroenterol Hepatol 12: 259-270.

39. Cabre M, Serra-Prat M, Palomera E, Almirall J, Pallares R, et al. (2010) Prevalence and prognostic implications of dysphagia in elderly patients with pneumonia. Age Ageing 39: 39-45.

40. Teramoto S, Fukuchi Y, Sasaki H, Sato K, Sekizawa K, et al. (2008) High incidence of aspiration pneumonia in community- and hospital-acquired pneumonia in hospitalized patients: a multicenter, prospective study in Japan. J Am Geriatr Soc 56: 577-579.

41. Holland G, Jayasekeran V, Pendleton $\mathrm{N}$, Horan $\mathrm{M}$, Jones $\mathrm{M}$, et al. (2011) Prevalence and symptom profiling of oropharyngeal dysphagia in a community dwelling of an elderly population: a self-reporting questionnaire survey. Diseases of the Esophagus 24: 476-80.
42. Roy N, Stemple J, Merrill RM, Thomas L (2007) Dysphagia in the elderly: preliminary evidence of prevalence, risk factors, and socioemotional effects. Ann Otol Rhinol Laryngol 116: 858-865.

43. Kawashima K, Motohashi Y, Fujishima I (2004) Prevalence of dysphagia among community-dwelling elderly individuals as estimated using a questionnaire for dysphagia screening. Dysphagia 19: 266-271.

44. Yang EJ, Kim MH, Lim JY, Paik NJ (2013) Oropharyngeal Dysphagia in a community-based elderly cohort: the korean longitudinal study on health and aging. J Korean Med Sci 28: 1534-1539.

45. Barczi SR, Sullivan PA, Robbins J (2000) How should dysphagia care of older adults differ? Establishing optimal practice patterns. Semin Speech Lang 21: 347-361.

46. Sura L, Madhavan A, Carnaby G, Crary MA (2012) Dysphagia in the elderly: management and nutritional considerations. Clin Interv Aging 7: 287-298.

47. Serra-Prat M, Hinojosa G, López D, Juan M, Fabré E, et al. (2011) Prevalence of oropharyngeal dysphagia and impaired safety and efficacy of swallow in independently living older persons. J Am Geriatr Soc 59: 186-187.

48. Lee A, Sitoh YY, Lieu PK, Phua SY, Chin JJ (1999) Swallowing impairment and feeding dependency in the hospitalised elderly. Ann Acad Med Singapore 28: 371-376.

49. Cabré $M$, Serra-Prat $M$, Force $L$, Almirall J, Palomera $E$, et al. (2014) Oropharyngeal dysphagia is a risk factor for readmission for pneumonia in the very elderly persons: observational prospective study. J Gerontol A Biol Sci Med Sci 69: 330-337.

50. Almirall J, Cabre M, Clave P (2012) Complications of Oropharyngeal Dysphagia:Aspiration Pneumonia. In: Cichero J, Clave P, editors. Stepping Stones to Living Well with Dysphagia. Basel: Karger 67-76.

51. Lin LC, Wu SC, Chen HS, Wang TG, Chen MY (2002) Prevalence of impaired swallowing in institutionalized older people in taiwan. J Am Geriatr Soc 50: 1118-1123.

52. Kalf JG, de Swart BJ, Bloem BR, Munneke M (2012) Prevalence of oropharyngeal dysphagia in Parkinson's disease: a metaanalysis. Parkinsonism Relat Disord 18: 311-315.

53. Langmore SE, Olney RK, Lomen-Hoerth C, Miller BL (2007) Dysphagia in patients with frontotemporal lobar dementia. Arch Neurol 64: 58-62.

54. Horner J, Alberts MJ, Dawson DV, Cook GM (1994) Swallowing in Alzheimer's disease. Alzheimer Dis Assoc Disord 8: 177-189.

55. Ikeda M, Brown J, Holland AJ, Fukuhara R, Hodges JR (2002) Changes in appetite, food preference, and eating habits in frontotemporal dementia and Alzheimer's disease. J Neurol Neurosurg Psychiatry 73: 371-376.

56. Suh MK, Kim H, Na DL (2009) Dysphagia in patients with dementia: Alzheimer versus vascular. Alzheimer Dis Assoc Disord 23: 178-184.

57. De Pauw A, Dejaeger E, D'hooghe B, Carton H (2002) Dysphagia in multiple sclerosis. Clin Neurol Neurosurg 104: 345-351.

58. Calcagno P, Ruoppolo G, Grasso MG, De Vincentiis M, Paolucci S (2002) Dysphagia in multiple sclerosis - prevalence and prognostic factors. Acta Neurol Scand 105: 40-43.

59. Chen A, Garrett CG (2005) Otolaryngologic presentations of amyotrophic lateralsclerosis. Otolaryngol Head Neck Surg 132: 500-504. 
60. Ruoppolo G, Schettino I, Frasca V, Giacomelli E, Prosperini L, et al. (2013) Dysphagia in amyotrophic lateral sclerosis: prevalence and clinical findings. Acta Neurol Scand 128: 397-401.

61. Martino R, Foley N, Bhogal S, Diamant N, Speechley $M$, et al. (2005) Dysphagia after stroke: incidence, diagnosis, and pulmonary complications. Stroke 36: 2756-2763.

62. Smithard DG, O'Neill PA, England RE, Park CL, Wyatt R, et al. (1997) The natural history of dysphagia following a stroke. Dysphagia 12: 188-193.

63. Robbins J (1996) Normal swallowing and aging. Semin Neurol 16: 309-317.

64. Robbins J (1999) Old swallowing and dysphagia: Thoughts on intervention and prevention. Nutr Clin Pract 14: S21-S26.

65. Rofes L, Arreola V, Romea M, Palomera E, Almirall J, et al. (2010) Pathophysiology of oropharyngeal dysphagia in the frail elderly. Neurogastroenterol Motil 22: 851-858.

66. Carrión S, Cabre M, Monteis R, Roca M, Palomera E, et al. (2014) Oropharyngeal dysphagia is a prevalent risk factor for malnutrition in a cohort of older patients admitted with an acute disease to a general hospital. Clinical Nutrition 34: 436-442.

67. Kikawada M, Iwamoto T, Takasaki M (2005) Aspiration and infection in the elderly : epidemiology, diagnosis and management. Drugs Aging 22: 115-130.

68. Ortega O, Cabre M, Clave P (2014) Oropharyngeal dysphagia: aetiology and effects of ageing. Journal of Gastroenterology and Hepatology Research 3: 1049-1054.

69. Han M, Ohnishi H, Nonaka M, Yamauchi R, Hozuki T, et al. (2011) Relationship between dysphagia and depressive states in patients with Parkinson's disease. Parkinsonism Relat Disord 17: 437-439.

70. Verdonschot RJCG, Baijens LWJ, Serroyen JL, Leue C, Kremer B (2013) Symptoms of anxiety and depression assessed with the Hospital Anxiety and Depression Scale in patients with oropharyngeal dysphagia. J Psychosom Res 75: 451-455.

71. Leow LP, Huckabee ML, Anderson T, Beckert L (2010) The impact of dysphagia on quality of life in ageing and Parkinson's disease as measured by the swallowing quality of life (SWAL-QOL) questionnaire. Dysphagia 25: 216-220.

72. García-Peris P, Parón L, Velasco C, de la Cuerda C, Camblor M, et al. (2007) Long-term prevalence of oropharyngeal dysphagia in head and neck cancer patients: Impact on quality of life. Clin Nutr 26: 710-717.

73. Turley R, Cohen S (2009) Impact of voice and swallowing problems in the elderly. Otolaryngol Head Neck Surg 140: 33-36.

74. Reuben DB (1991) Geriatrics syndromes. In: Beck AC (ed.) Geriatrics Review Syllabus (2nd edn.) New York: American Geriatrics Society 117-231.

75. Speyer R, Baijens L, Heijnen M, Zwijnenberg I (2010) Effects of therapy in oropharyngeal dysphagia by speech and language therapists: a systematic review. Dysphagia 25: 40-65.

76. Shaker R, Lang IM (1994) Effect of aging on the deglutitive oral, pharyngeal, and esophageal motor function. Dysphagia 9: 221-228.

77. Ueda K, Yamada Y, Toyosato A, Nomura S, Saitho E (2004) Effects of functional training of dysphagia to prevent pneumonia for patients on tube feeding. Gerodontology 21: 108-111.

78. Warusevitane A, Karunatilake D, Sim J, Lally F, Roffe C (2015) Safety and effect of metoclopramide to prevent pneumonia in patients with stroke fed via nasogastric tubes trial. Stroke 46: 454-460.

79. Kalra L, Irshad S, Hodsoll J, Simpson M, Gulliford M, et al. (2015) Prophylactic antibiotics after acute stroke for reducing pneumonia in patients with dysphagia (STROKE-INF): a randomised prospective,cluster randomised, open label trial. Lancet 386:1835-1844.

80. Westendorp WF, Vermeij JD, Zock E2, Hooijenga IJ, Kruyt ND, et al. (2015) The Preventive Antibiotics in Stroke Study (PASS): a pragmatic randomised open-label masked endpoint clinical trial. Lancet 385: 1519-1526.

81. Cruz-Jentoft AJ, Michel JP (2013) Sarcopenia: a useful paradigm for physical frailty. Eur Geriatr Med 4: 102-105.

82. Martin FC (2009) Next steps for falls and fracture reduction. Age Ageing 38: 640-643. 